\title{
Coronavirus e Sistema Socioeducativo no Estado do Rio de Janeiro: Como fica a saúde dos adolescentes privados de liberdade?
}

\section{| ${ }^{1}$ Daiane Oliveira I}

1 Instituto de Medicina Social, Universidade do Estado do Rio de Janeiro-RJ, Brasil (daycarvalho21@gmail.com). ORCID: 0000-0002-5727-3638

O presente comentário apresenta as açóes adotadas pelo Estado do Rio de Janeiro no enfrentamento ao coronavírus no sistema socioeducativo, buscando refletir sobre sua efetividade na garantia da atenção Integral à saúde dos adolescentes em cumprimento de medida socioeducativa de privação e restrição de liberdade.

$\mathrm{Na}$ construção deste processo reflexivo, inicialmente, iremos contextualizar as bases normativas para a execução da política socioeducativa no Brasil e para a atenção integral à saúde do adolescente em cumprimento de medida socioeducativa. Em seguida, apresentaremos as açôes adotadas pela Secretaria Estadual de Saúde (SES-RJ) e pelo Departamento Geral de Açóes Socioeducativas (DEGASE) no enfrentamento ao coronavírus; por fim, realizaremos uma reflexão sobre como a política neoliberal, com a redução de investimentos em políticas públicas e o avanço do autoritarismo, vem impossibilitando respostas imediatas e efetivas à garantia da saúde do adolescente privado de liberdade.

No Brasil, a Constituição Federal (1988) incorpora a concepção de direito e cidadania plena à população infanto-juvenil, substituindo a doutrina da situação irregular do Código de Menores pela doutrina da proteçấo integral prevista no Estatuto da Criança e do Adolescente - ECA (1990). O ECA reconhece os direitos 
universais e integrais desses sujeitos, sua condição peculiar de desenvolvimento, a prioridade absoluta na destinação de recursos na formulação e execução de políticas públicas, a primazia de atendimento e a responsabilização e aplicação de medidas socioeducativas aos adolescentes que cometem atos infracionais.

A Resoluçáo no 119/2006, do Conselho Nacional dos Direitos da Criança e do Adolescente (CONANDA), criou o Sistema Nacional de Atendimento Socioeducativo (SINASE), sendo posteriormente instituído pela Lei Federal $n^{\circ}$ 12.594/2012, que normatiza as bases para a organização do sistema, estabelecendo os princípios, regras e critérios que envolvem a execução de medidas socioeducativas, e reafirma a perspectiva da garantia dos direitos dos/as adolescentes, inclusive o direito à saúde.

O SINASE, em consonância com o princípio da incompletude institucional, confere ao Sistema Único de Saúde (SUS) a responsabilidade pela atenção integral à saúde dos adolescentes e jovens em atendimento socioeducativo em meio aberto, fechado e restrição de liberdade. Dessa forma, o Ministério da Saúde, desde o ano de 2004, vem se dedicando a construção e normatização da Política Nacional de Atenção Integral à Saúde de Adolescentes em Conflito com a Lei (PNAISARI) e em 2014, redefiniu as diretrizes da política, com a publicação das Portarias no ${ }^{\circ}$ 1.082 e 1.083, objetivando a garantia e a ampliação do acesso ao cuidado em saúde e definindo aos municípios a responsabilidade sanitária por essa população.

No Estado do Rio de Janeiro, o DEGASE, vinculado à Secretaria de Educaçáo (SEEDUC), é o órgão do Poder Executivo responsável pela execução das medidas socioeducativas de restrição e privação de liberdade, preconizadas pelo Estatuto da Criança e do Adolescente (ECA) e aplicadas pelo Poder Judiciário. Sua estrutura é formada por nove Centros de Socioeducação, unidades de cumprimento da medida socioeducativa de privação de liberdade, e 16 Centros de Recursos Integrados de Atendimento ao Adolescente (CRIAAD), unidades de atendimento de medida socioeducativa de semiliberdade, localizados nos municípios de Rio de Janeiro, Niterói, São Gonçalo, Nova Iguaçu, Duque de Caxias, Belford Roxo, Nilópolis, Cabo Frio, Macaé, Volta Redonda, Barra Mansa, Nova Friburgo, Campos e Teresópolis.

O DEGASE, através da Coordenação de Saúde Integral e Reinserção Social (CSIRS), estruturou a organização das ações de saúde nas unidades de internação, internação provisória e semiliberdade considerando os princípios previstos no SUS, na Política Nacional de Humanização, na Política Nacional de Atenção Básica e na 
PNAISARI. A atuação da CSIRS pauta-se no reconhecimento de que a prática do ato infracional não anula a condição peculiar do adolescente enquanto pessoa em desenvolvimento e portadora de direitos humanos, sendo imprescindível o respeito a sua integridade física e mental, o enfrentamento ao estigma e preconceito, e a garantia da integralidade e humanização no cuidado.

Com a declaração da Organização Mundial da Saúde (OMS) em 30 de janeiro de 2020, sobre situação de Emergência em Saúde Pública de Importância Internacional (ESPII) por doença respiratória causada pelo coronavírus (Covid-19) e a publicação, em 12 de março de 2020, pelo Ministério da Saúde, da Portaria no 356 de 11/03/2020, o DEGASE elaborou planos operacionais padróes, protocolos, diretrizes operacionais e adequação dos fluxos de saúde, buscando a prevenção ao coronavírus no sistema socioeducativo. Essa produção técnica considerou a necessidade de respostas imediatas e tomada de decisóes apoiadas nas evidências técnicas de ciência e saúde, e seguiu as orientações e recomendações da OMS, do Ministério da Saúde, da SES-RJ, da Fundação Oswaldo Cruz (Fiocruz) e do sistema de garantia de direitos da criança e do adolescente.

Dentre os protocolos elaborados, o Plano Operacional Padrão (POP) e o documento "Estratégias para Enfrentamento da Pandemia do Covid-19 em Unidades de Privação de Liberdade do DEGASE” definem as ações de saúde específicas a serem adotadas no fluxo das unidades socioeducativas de privação e restrição de liberdade para o controle, monitoramento e assistência aos casos suspeitos e confirmados para o novo coronavírus. Entre as principais açóes definidas, constam: a prioridade da recepçáo de saúde na porta de entrada do adolescente no sistema socioeducativo, a identificação de sinais e sintomas de síndromes gripais e comorbidades de risco para a Covid-19, prevenção terciária com imunização para $\mathrm{H} 1 \mathrm{~N} 1$, destinação de alojamentos específicos para isolamento respiratório e para quarentena dos adolescentes recémchegados ao sistema, açôes de promoção da saúde mental, orientaçôes para o manejo clínico dos sintomáticos respiratórios e busca ativa nos alojamentos para avaliação e acompanhamento em saúde.

As Secretarias Municipais de Saúde do Rio de Janeiro,Volta Redonda, Campos do Goytacazes, Belford Roxo e Nova Friburgo, municípios com unidade socioeducativa de privação de liberdade, seguindo as orientaçôes da Secretaria Estadual de Saúde e considerando os protocolos e fluxos elaborados pela CSIRS, construíram os Planos de Contingência Municipais para o Enfrentamento ao Coronavirus no Socioeducativo, 
definindo as ações de prevenção e assistência à saúde e critérios para a realização da testagem para Covid-19, exames complementares, notificação obrigatória dos casos suspeitos e confirmados e acesso à atenção hospitalar, caso necessário. A efetivação dessas açóes de saúde acontece de forma híbrida, sendo algumas realizadas pelos profissionais de saúde do DEGASE e outras na rede municipal de saúde.

As açôes de biossegurança foram intensificadas com a disponibilização de equipamento de proteção individual (EPI) para os profissionais de saúde e, posteriormente, para os agentes socioeducativos, equipe técnica e adolescentes. Todos os espaços físicos das unidades socioeducativas, incluindo o alojamento dos adolescentes, são higienizados frequentemente com uso de pulverizadores e produtos como hipoclorito, detergente ou álcool 70\%; foram também instalados dispensers para álcool em gel e sabonete líquido, além de porta-toalha em todas as unidades socioeducativas.

Seguindo as recomendaçóes da Resolução SES/SEEDUC no 737, de 16 de março de 2020, que promove recomendaçóes para prevenção e controle de infecçóes pelo novo coronavírus (Covid-19) a serem adotadas nas Unidades Socioeducativas do Estado do Rio de Janeiro, o DEGASE suspendeu temporariamente as visitas de famílias nas unidades de internação e internação provisória, e a SEEDUC suspendeu as aulas escolares. Com a suspensão das visitas, o direito à convivência familiar vem sendo garantido através da comunicação através de telefone e mídias digitais.

A necessidade da suspensão das visitas de famílias e das aulas escolares no DEGASE foi justificada pela SES/SEEDUC, devido ao ambiente de privação de liberdade ser de alto risco de transmissibilidade para o coronavírus. Contudo, no documento "Estratégias para Enfrentamento da Pandemia do Covid-19 em Unidades de Privação de Liberdade do DEGASE", tais medidas restritivas foram apontadas como fatores de risco para a saúde mental e para o surgimento de casos de sofrimento psíquico, estresse e ansiedade entre os adolescentes.

Entre as principais estratégias para proteçáo da vida dos adolescentes em atendimento socioeducativo, a CSIRS seguiu a Recomendação no 62, de 17 de março de 2020, do Conselho Nacional de Justiça, que recomenda aos tribunais e magistrados a adoção de medidas preventivas à propagação da infecção pelo novo coronavírus (Covid-19) no âmbito dos sistemas de justiça penal e socioeducativo. Dentre as recomendaçôes aos magistrados foi prevista a reavaliação de medidas socioeducativas de internação e semiliberdade, para substituição por medida em 
meio aberto, em especial para adolescentes com comorbidades. Nesta direção, a CSIRS elaborou orientaçôes técnicas aos profissionais de saúde médicos e enfermeiros do DEGASE sobre a necessidade de emissão de laudo e documentos técnicos das condiçóes de saúde dos adolescentes pertencentes ao grupo de risco para Covid-19, objetivando a apreciação do Judiciário e uma possível substituição para medida socioeducativa em meio aberto. Os adolescentes com transtornos mentais, sofrimento psíquico associado a autoagressão ou autolesão e com ideação suicida foram considerados, nestas orientaçôes, como pertencentes ao grupo de risco.

$\mathrm{Na}$ análise dos documentos elaborados pela SES-RJ e pelo DEGASE no enfrentamento ao coronavírus, identificou-se que foram construídas respostas técnicas e articuladas entre os entes federativos na perspectiva da garantia do direito à saúde dos adolescentes privados de liberdade. Contudo, ainda é necessário olharmos para o monitoramento dessas açóes, a fim de verificar sua efetividade.

\section{Entre o legal e o real: impasses para a garantia da saúde de adolescentes privados de liberdade em tempos de pandemia}

A pandemia do coronavírus desnudou as fragilidades históricas que impossibilitaram a real consolidação do SUS. O neoliberalismo implantado no Brasil a partir da década de 1990, com ajuste fiscal e redução da máquina pública e dos investimentos em políticas sociais, é um entrave econômico à efetivação do projeto de seguridade social normatizado na Constituição Federal de 1988. É consenso entre alguns autores do campo da Saúde Coletiva que o SUS é subfinanciado desde sua origem, mas ao longo dos anos houve gradativas açóes para sua implementação com prioridades distintas na agenda governamental de acordo com o cenário político do país.

Considerando a política de saúde destinada à população de adolescentes em cumprimento de medida socioeducativa, apenas no ano de 2004, 14 anos após as Leis $\mathrm{n}^{\circ} \mathrm{S}$ 8.080, que dispóe sobre a organização e funcionamento do SUS, e 8.069, que dispóe sobre o Estatuto da Criança e do Adolescente, serem sancionadas, houve um esforço do Ministério da Saúde com a publicação da Portaria Interministerial no 1.426 na construção de uma política nacional que buscou articular o SUS com o sistema socioeducativo. Essa iniciativa fortaleceu a doutrina da proteção integral e reconheceu os adolescentes em conflito com a lei enquanto sujeitos de direitos. 
Nesse período, segundo análise de Levcovitz e Couto (2018), em relação aos sistemas de saúde na América Latina no século XXI, o Brasil vivia a denominada "Maré Rosa", com a ascensão do Partido dos Trabalhadores, adoção de políticas macroeconômicas de fortalecimento das capacidades fiscais dos Estados e aumento do gasto público social. No período de oito anos do governo do presidente Lula, houve maior enfoque nas ações que buscaram a melhoria nas condiçóes de vida e nos determinantes sociais da saúde. Contribuiu-se para a garantia da saúde dos adolescentes e jovens em cumprimento de medida socioeducativa, visto que parcela significativa dessa população vive em situação de vulnerabilidade e risco social. Essa agenda, apesar de todos os limites que envolvem subfinanciamento do sistema de saúde, teve continuidade no governo da presidenta Dilma Rousseff.

No ano de 2012, realizou-se concurso público para provimento de vagas em diferentes cargos no DEGASE, possibilitando ampliação de um corpo técnico de servidores estatutários e qualificados no sistema socioeducativo do Estado do Rio de Janeiro. A partir do ano de 2014, a CSIRS, em articulação com a Secretaria Estadual de Saúde, intensificou o processo de assessoramento aos municípios para a implementação da PNAISARI, resultando na habilitação, pelo Ministério da Saúde, de dez municípios dentre os 14 com unidades socioeducativas.

A PNAISARI e o fortalecimento intersetorial entre as políticas públicas contribuíram para a superação de impasses sobre qual o ente federativo tem a responsabilidade pelo cuidado e para a diminuição do preconceito, estigma e iniquidades em saúde atribuída a essa população. Todavia, o processo de impeachment da presidenta Dilma Rousseff no ano de 2016 interrompeu essa agenda e enfraqueceu a capacidade de atuação dos municípios em atender às diretrizes da política.

O governo Temer caracterizou a retomada, com força total, da proposta neoliberal e dos interesses privatistas do SUS. A aprovação da Ementa Constitucional no 95, instituindo o novo regime fiscal de austeridade econômica, enfraqueceu a capacidade de resposta do Estado na proteção social. Atualmente, a maior dificuldade para a garantia da saúde desses adolescentes ocorreu devido à redução de investimentos em políticas públicas que considerem os determinantes sociais do processo saúde e doença, do subfinanciamento do SUS e da crise na saúde pública que acomete toda a população do Estado do Rio de Janeiro.

É nesse cenário, agravado com o atual governo neoliberal de extrema direita, caracterizado pelo jurista Casara (2017), de Estado pós-democrático, que precisamos 
enfrentar a pandemia de coronavírus. O Estado pós-democrático, segundo Casara, é o Estado compatível com o neoliberalismo, que atende aos interesses do mercado e do ultraliberalismo econômico com tendências arbitrárias e autoritárias, sem qualquer limite efetivo ao exercício do poder e da transformação de toda prática humana em mercadoria. Além da soberania do mercado, que impede o necessário investimento de recursos financeiros no SUS para o enfrentamento do coronavírus, presenciamos a atuação de uma personalidade autoritária no comando do país que despreza as orientações das autoridades sanitárias e impossibilita uma coordenação adequada entre as instâncias federais, estaduais e municipais de saúde diante da grave crise sanitária.

O reflexo desse cenário no sistema socioeducativo do Estado do Rio de Janeiro se materializa no abismo entre as orientaçóes e recomendaçóes previstas nos Planos de Contingência Municipais para o Enfretamento ao Coronavírus e sua real efetivação no cotidiano das unidades. Esse abismo é alimentado pela insuficiência de financiamento federal aos municípios, enfraquecendo sua capacidade de atuação diante da pandemia e na proteção à saúde dos adolescentes privados de liberdade. Para termos uma ideia, se tomarmos como exemplo o município do Rio de Janeiro, é possível verificar que o mesmo aguarda seu processo de habilitação na PNAISARI pelo Ministério da Saúde e repasse de incentivo financeiro de custeio desde o ano de 2018.

$\mathrm{Na}$ atual conjuntura, foi possível observar que os municípios de Volta Redonda, Belford Roxo e Campos do Goytacazes, habilitados na PNAISARI, vêm conseguindo, apesar das dificuldades, realizar as açôes de saúde previstas nos Planos de Contingência Municipais de forma articulada entre o SUS e o socioeducativo.

Em direção contrária seguem os municípios do Rio de Janeiro e Nova Friburgo, que mesmo tendo construído seus Planos de Contingência Municipais delegam ao socioeducativo a realização das açóes de saúde no interior das unidades, assumindo a responsabilidade apenas das campanhas de imunização e no cuidado dos adolescentes encaminhados à rede municipal. A direção adotada pela gestão de saúde desses municípios, associada à ausência do profissional médico e/ou enfermeiro nas unidades socioeducativas, impossibilita a efetivação das açôes propostas ao enfretamento do coronavírus.

Um cenário comum a todos os municípios com unidades de privação e restrição de liberdade é o déficit de profissionais de saúde no SUS, a baixa cobertura de 
testagem para Covid-19, a insuficiência de leitos hospitalares e a flexibilização das medidas de proteção individual por parte de alguns profissionais do DEGASE, principalmente os da área de segurança, que minimizam o risco de letalidade da doença e fortalecem o famoso discurso da "gripezinha".

\section{Referências}

BRASIL. Governo do Estado do Rio de Janeiro. Resolução SES/SEEDUC no 737, de 16 de março de 2020. Disponível em: <https://coronavirus.rj.gov.br/wpcontent/uploads/2020/03/ Resolu\%C3\%A7\%C3\%A3o_SES_SEEDUC_16.03.2020.pdf>.

Ministério da Saúde. Portaria $n^{\circ}$ 1.082, de 23 de maio de 2014. Redefine as diretrizes da Política de Atenção Integral a Saúde de Adolescentes em Conflito com a Lei (PNAISARI). Disponível em: <http://bvsms.saude.gov.br/bvs/saudelegis/gm/2014/ prt1082_23_05_2014.html>.

. Presidência da República. Casa Civil. Lei Federal n 8.069, de 13 de julho de 1990a. Dispóe sobre o Estatuto da Criança e do Adolescente e dá outras providências. Disponível em: $<$ http://www.planalto.gov.br/ccivil_03/leis/18069.htm>.

. Presidência da República. Casa Civil. Lei Federal no 8.080/90, de 19 de setembro de 1990b. Dispóe sobre as condições para a promoção, proteçấo e recuperação da saúde, a organização e o funcionamento dos serviços correspondentes e dá outras providências. Disponível em: <http://www.planalto.gov.br/ccivil_03/leis/18080.htm>.

CASARA, R. Estado pós-democrático: neo-obscuratismo e gestão dos indesejáveis. Rio de Janeiro: Civilização Brasileira, 2017.

CONSELHO NACIONAL DE JUSTIÇA. Recomendação no 62, de 17 de março de 2020. Disponível em: <https://www.cnj.jus.br/wp-content/uploads/2020/03/62 Recomenda\%C3\%A7\%C3\%A3o.pdf>.

DEPARTAMENTO GERAL DE AÇÓES SOCIOEDUCATIVAS. Estratégias para Enfrentamento da Pandemia do Covid-19 em Unidades de Privação de Liberdade do DEGASE. Rio de Janeiro: CSIRS, 2020.

- Protocolo Operacional Padrão de Enfrentamento ao Coronavírus no Sistema Socioeducativa. Rio de Janeiro: CSIRS, 2020.

LEVCOVITZ, E.; COSTA-COUTO, M. H. Sistemas de Saúde na América Latina no século XXI. In: NOGUEIRA, R. P. et al. (Orgs.). Observatório Internacional de Capacidades Humanas, Desenvolvimento e Politicas Públicas: estudos e análises. Brasília: Nesp/Ceam/UnB-Nethis/ Fiocruz, 2018. p. 99-118. 